\title{
Exploring the barriers and facilitators to non-medical prescribing experienced by pharmacists and physiotherapists, using focus groups
}

\author{
Emma Graham-Clarke ${ }^{1^{*}} \mathbb{0}$, Alison Rushton ${ }^{2}$ and John Marriott ${ }^{1}$
}

\begin{abstract}
Background: Non-medical prescribing (NMP) was introduced into the United Kingdom to enhance patient care and improve access to medicines. Early research indicated that not all non-medical prescribers utilised their qualification. A systematic review described 15 factors influencing NMP implementation. Findings from a recent linked Delphi study with independent physiotherapist and pharmacist prescribers achieved consensus for 1 barrier and 28 facilitators. However, item ranking differed for pharmacist and physiotherapist groups, suggesting facilitators and barriers to NMP differ depending on profession. The aim of this study was to further explore the lived experiences of NMP by pharmacists and physiotherapists.

Method: Study design and analytical approach were guided by Interpretative Phenomenology Analysis principles. Focus groups (November and December 2020) used the 'Zoom ${ }^{\circledR /}$ virtual platform with pharmacist and physiotherapist prescribers. Each focus group followed a topic guide, developed a priori based on the Delphi study results, and was audio recorded digitally. Transcripts underwent thematic analysis and data were visualised using a concept map and sunburst graph, and a table of illustrative quotes produced. Research trustworthiness was enhanced through critical discussion of the topic guide and study findings by the research group and by author reflexivity. The study is reported in line with COREQ guidelines.

Results: Participants comprised three physiotherapists and seven pharmacists. Five themes were identified. The most frequently mentioned theme was 'Staff', and the subtheme 'Clinical team', describing the working relationship between participants and team members. The other themes were 'Self,',Governance,',Practical aspects' and 'Patient care'. Important inter-dependencies were described between themes and subthemes, for example between 'Governance' and 'Quality and Safety.' Differences were highlighted between the professions, some relating to the way each profession practises (for example decision making), others to the way the prescribing role had been established (for example administration support).
\end{abstract}

Conclusions: The key finding of collaborative working with the clinical team emphasises its impact on successful implementation of NMP. Themes may be inter-dependent, and inter-profession differences were identified.

\footnotetext{
*Correspondence: EMG315@student.bham.ac.uk

${ }^{1}$ School of Pharmacy, Institute of Clinical Sciences, College of Medical

and Dental Sciences, University of Birmingham, Birmingham, UK

Full list of author information is available at the end of the article
}

(c) The Author(s) 2022. Open Access This article is licensed under a Creative Commons Attribution 4.0 International License, which permits use, sharing, adaptation, distribution and reproduction in any medium or format, as long as you give appropriate credit to the original author(s) and the source, provide a link to the Creative Commons licence, and indicate if changes were made. The images or other third party material in this article are included in the article's Creative Commons licence, unless indicated otherwise in a credit line to the material. If material is not included in the article's Creative Commons licence and your intended use is not permitted by statutory regulation or exceeds the permitted use, you will need to obtain permission directly from the copyright holder. To view a copy of this licence, visit http://creativecommons.org/licenses/by/4.0/. The Creative Commons Public Domain Dedication waiver (http://creativeco mmons.org/publicdomain/zero/1.0/) applies to the data made available in this article, unless otherwise stated in a credit line to the data. 
Specifically designed prescribing roles were beneficial for participants. For full NMP benefits to be realised all aspects of such roles must be fully scoped, before recruiting or training non-medical prescribers.

Keywords: Barriers, Facilitators, Pharmacist, Physiotherapist, Prescribing

\section{Background}

Non-medical prescribing (NMP) was introduced into the United Kingdom (UK) to enhance patient care and improve access to medicines [1]. Initially this enabled district nurses and health visitors to prescribe from a limited formulary [2] but in 1999, following the second Crown Report, the concept of independent and supplementary prescribing for nurses and other healthcare professionals was introduced [3]. Since then, the number of professions with independent prescribing rights has gradually increased and now includes nursing, optometry, pharmacy, podiatry, physiotherapy, paramedics and therapeutic radiography [4]. Demand exists for other professions to gain independent prescribing rights, with the Health Foundation commenting that until physician associates are able to prescribe independently, they will be limited in their activities [5]. Since the introduction of NMP, the UK National Health Service (NHS) has experienced increased patient demand, workforce shortage pressures, and funding shortfalls, driving policy emphasis to provision of streamlined care for patients, with NMP playing a pivotal role [6-8]. For example, prescribing physiotherapists, the first point of contact for many patients with musculoskeletal problems, are able to provide the complete treatment course without referral to other healthcare professionals $[7,9,10]$. A further example is that of pharmacists involved in the care of long term conditions [11]. These plans will be hindered if qualified nonmedical prescribers are deterred, for whatever reason, from utilising their skills. Earlier research indicated that approximately $25 \%$ of Allied Health Professionals, qualified as prescribers, may not use this skill in comparison to $10 \%$ of qualified prescribing nurses [12, 13]. Establishing factors that facilitate or prevent NMP and investigating if these are generic to different NMP professions, or are professional, situational or person specific will aid NMP development.

A previous systematic review described 15 factors or themes that had the potential to influence the implementation of prescribing by non-medical professions [14]. It was noted that the majority of the included studies focused on prescribing by nurses, with the remainder addressing prescribing by pharmacists. The four most common themes identified included the influence of medical staff, the prescriber's area of competence, the impact on their time and impact on service. No papers were found that reviewed the experiences of any other
NMP profession. It is unclear whether or not the factors that affect prescribing by nurses and pharmacists are also experienced by other non-medical prescribing professions, or if they experience different factors.

To investigate this further a three round Delphi study investigating facilitators and barriers to independent non-medical prescribing was conducted with qualified independent prescribers from an established prescribing profession (pharmacy) and a newer, and relatively unexamined, prescribing profession (physiotherapy) [15]. The two professions were chosen as they have similar numbers of registrants in the UK (approximately 56,000), may work as individuals or in teams, and may work in all healthcare sectors $[16,17]$. They differ in the length of time that each profession has had prescribing rights, with pharmacy gaining independent prescribing rights six years earlier than physiotherapy $[18,19]$. Consensus was gained for 1 barrier and 28 facilitators, however, item ranking orders differed for the pharmacist and physiotherapist groups. This suggested that the facilitators and barriers to NMP differ depending on profession. However, it was possible that the differences arose from chance and did not accurately reflect experiences.

This paper presents the results of focus groups to further investigate the findings of the Delphi study, to explore if the findings reflected the experiences of pharmacist and physiotherapist prescribers, or if additional factors affecting implementation of NMP were also present. This would indicate how generalisable the Delphi study findings are to the wider pharmacist and physiotherapist prescribing populations.

\section{Aim}

To further explore the lived experiences of non-medical prescribing by pharmacists and physiotherapists.

\section{Method}

Research team and reflexivity

EGC, JM and AR developed the study protocol and topic guide and EGC conducted the focus groups. EGC is a doctoral student, researching influences affecting NMP utilisation and inter-professional differences. The research question was prompted by her activity as an independent pharmacist prescriber, and her role as NMP lead for an acute NHS Trust in the Midlands. Her researcher standpoint is balanced by the other two researchers, neither of whom is a prescriber, but who 
have extensive research experience and represent the pharmacy and physiotherapy professions.

EGC acted as the contact point for participants during recruitment. Participants were made aware of the background to the research via the participant information sheet, issued at the time of recruitment, and this information was reinforced at the start of each focus group.

\section{Study design}

The study design and analytical approach were guided by the principles of Interpretative Phenomenology Analysis (IPA) [20]. IPA acknowledges that the lived experience of each participant reflects their world view, and that interpretation is affected by the researcher's own experiences. This study sought to understand how non-medical prescribers perceived their practice was affected by outside influences, whether procedural or people. Each participant will have had different formative experiences, shaping their view of NMP, and IPA will aid in interpretation of this, whilst recognising the potential influence of the lead researcher.

Focus groups enable discussion between participants on selected specific topics. The discussion and interaction between the participants allow ideas and views to be developed and refined, and thus provide a deeper understanding of the issues being considered [21, 22]. There is also the potential for unanticipated ideas to be expressed, supporting further understanding of the research topic [22]. Research indicates that $80 \%$ of ideas are generated within the first two or three focus groups, and these comprise the most frequently mentioned themes [23, 24]. Furthermore, Hennink describes focussed research questions requiring fewer focus groups to generate ideas than research questions where the issues are unknown [25]. A pragmatic approach to the groups was adopted, balancing available resources and the level of information anticipated from the closely defined topic guide [25]. Two focus groups were planned, using the 'Zoom ${ }^{\circledR}$, virtual platform (Zoom.us), hosted by the University of
Birmingham. Each group was led by a moderator (EGC) and the conversation was audio recorded digitally, using the virtual platform record feature, and handwritten fieldnotes were taken. Each focus group followed a similar format of introduction, main discussion and closing stage, and followed an a priori developed topic guide [21, 26-28]. The topic guide was drafted by EGC, using the previous Delphi results as a guide, and debated within the research group to ensure that the guide was clear, followed a logical progression and was appropriate for the aim of the study (Additional File 1). The topics chosen were those where there were apparent differences in the Delphi results between the professions when reviewing the ranked statements by profession. The discussion was summarised after each topic and at the end of each focus group, enabling participants to comment and correct any misinterpretation.

\section{Choice of setting}

Focus groups are conventionally run face to face, using a location suitable for researchers and participants. However, to reduce transmission of Covid-19, people were advised to physically distance themselves, to meet outdoors rather than inside and to wear face masks [29], making physical meetings difficult to conduct. Virtual focus groups have been previously reported, with researchers using a variety of techniques such as message boards and video conferencing, with cost of equipment (e.g., webcams) and programmes listed as potential disadvantages $[30,31]$. The restrictions imposed to limit the spread of Covid-19 accelerated the widespread adoption of virtual meeting platforms such Zoom ${ }^{\circledR}$ for both work and social uses. Indeed, many participants in this study described the benefits of online meetings, indicating that many of the earlier challenges with virtual platforms, such as equipment availability, had been overcome. Table 1 lists potential advantages and disadvantages of physical (under Covid-19 restrictions) and virtual meetings. The

Table 1 Comparison of physical and virtual meetings for focus groups

\begin{tabular}{|c|c|c|}
\hline & Physical meeting, under Covid-19 restrictions & Virtual meeting \\
\hline Advantages & $\begin{array}{l}\text { No special equipment required e.g., cameras } \\
\text { Conversation and discussion can flow easily } \\
\text { No specialist knowledge (e.g., computer literacy) required }\end{array}$ & $\begin{array}{l}\text { No travel required; participants may be able to join who would } \\
\text { otherwise be time restricted } \\
\text { Virtual platform includes record function } \\
\text { Face masks may not be required, dependent on participant's loca- } \\
\text { tion } \\
\text { Participants can join from any suitable location }\end{array}$ \\
\hline Disadvantages & $\begin{array}{l}\text { Large room required to enable social distancing } \\
\text { Face masks need to be worn, hiding facial expressions } \\
\text { Recording equipment required } \\
\text { Travel, and travel time, required to attend meeting location }\end{array}$ & $\begin{array}{l}\text { Only one person can speak at once, potentially stilting conversation } \\
\text { Depends on internet connectivity } \\
\text { Requires computer or smartphone or similar, with audio and camera } \\
\text { Participants required to have basic computer literacy }\end{array}$ \\
\hline
\end{tabular}


assessment was made that, with the ongoing pandemic associated restrictions, the virtual platform was the most appropriate technique to enable the focus groups to be conducted.

\section{Participants and recruitment}

Participants for the focus groups included independent prescribing pharmacists or physiotherapists working in primary or secondary care in the West Midlands region. No easily accessible list for pharmacist and physiotherapist independent prescribers was available and therefore participants were recruited indirectly using groups such as the United Kingdom Clinical Pharmacy Association and West Midlands NMP leads. An email, including study details, participant information sheet, screening questionnaire and contact email address, was sent to these groups and recipients were requested to forward the email to potential participants.

The number of qualified independent pharmacist and physiotherapist prescribers in the West Midlands region is unknown, as this information is recorded by individual healthcare providers, and not centrally. Therefore, the intention was to recruit 10 prescribing pharmacists and 10 prescribing physiotherapists, allowing for non-attendees, but providing sufficient participants for a meaningful discussion [21, 25, 32]. The literature on focus groups recommends a group size of 6 to 8 participants, with recommendations to over recruit by approximately $20 \%$ in case of nonattendance [21, 25, 32]. Participants were required to have obtained their prescribing qualification since the beginning of 2013 (when physiotherapists gained independent prescribing rights [19]), and the final selection was guided by the sample matrix in Table 2 .

Participants were asked to sign and return a consent form, including consent to record the focus group, prior to the focus group being conducted. Recruitment was closed in October 2020.

Table 2 Target sample matrix for focus group participants

\begin{tabular}{lllll}
\hline Criteria & Pharmacist & Physiotherapist & $\begin{array}{l}\text { Years of } \\
\text { professional } \\
\text { practice }\end{array}$ \\
\hline Profession & 10 & 10 & $\leq 5$ & $0-5$ \\
\multicolumn{2}{l}{$\begin{array}{l}\text { Length of time qualified as a prescriber: } \\
\geq 12 \text { months }\end{array} 1-6$} & $1-6$ & $6-10$ & $0-5$ \\
$\quad<12$ months & $1-6$ & $1-6$ & $11-15$ & $0-5$ \\
Main practice area: & & & $16-20$ & $0-5$ \\
Primary Care & $1-6$ & $1-6$ & $>21$ & $0-5$ \\
Secondary care & $1-6$ & $1-6$ & & \\
\hline
\end{tabular}

\section{Ethical considerations}

Ethical approval for the study was obtained from the University of Birmingham's Science, Technology, Engineering and Mathematics Ethical Review Committee (ERN_19-1900) and all data were held securely in accordance with university policy. Participation was voluntary and participants were free to withdraw at any time, however they were made aware that if they had already participated in the discussion, then it would not be possible to remove their contribution. All participants gave written consent, including for digital audio recording, prior to the focus group. All recordings were transcribed verbatim and anonymised to ensure that participants, locations, or other identifiable information were removed, and participants were assigned an identification code.

\section{Data analysis}

Digital transcripts of each conversation were produced by the virtual platform, and these were checked for accuracy, corrected, and verified by EGC. This process required repeated listening to the recording, hence ensuring all information was captured accurately, and permitting immersion in the data. Following transcription, data were imported into NVivo ${ }^{\circledR} 12$ (QSR International) for thematic analysis [21, 33, 34]. The transcript for Focus Group One was read and reread to identify emergent themes and patterns, and coded line by line, with new codes created as themes emerged. The process was repeated for Focus Group Two, with further themes added as they emerged. Coding was an iterative process, with repeat reviewing of the coded data to ensure consistency and initial thoughts on the findings recorded using the NVivo memo function. Finally, the themes were reviewed and consolidated where appropriate. A codebook was produced to support the coding process. Data was visualised using a concept map of the major and minor themes and interdependencies, and a sunburst graph which depicted the frequency that themes were mentioned. Quotations illustrating each theme were presented as a table (Table 4). The initial coding was done by EGC, and the themes and hierarchy were discussed critically by the research team.

The study is reported in accordance with the COREQ statement (Additional file 2) [35].

\section{Results}

Eighteen participants initially expressed an interest in participating in the focus groups. The recruitment window was extended, and further invitation emails sent to encourage further interest in participation, but the response remined low. The decision was taken to conduct the focus groups with the existing pool of potential 
participants, rather than risk a high dropout rate as participants were called to care for Covid-19 patients. Even with this approach, five potential participants who had previously expressed an interest failed to respond to the focus groups emails. A further three participants were excluded: two were ineligible, and dates were unsuitable for one, leaving ten participants. Three participants participated in Focus Group One and seven participated in Focus Group Two. Brief demographic data are included in Table 3. Focus Group One was held on 23 November 2020 in the evening and Focus Group Two on 3 December 2020 during the day, each lasting just over one hour.

Initial coding was reviewed by EGC by reading the results for each node coded and the matrix tool in NVivo utilised to check that coding was appropriate. A concept map of themes was derived by EGC following coding of the transcripts, and the map and derived themes were debated by EGC, AR and JM to ensure they reflected participants views. After further discussion, the hierarchy and concept map were re-drawn to reflect the lived experiences of the participants more accurately. For example the original hierarchy did not contain a 'self' theme and hence 'personal competence' was grouped under 'governance' instead. However, as this quote highlights, 'personal competence' is derived from the participant's views and feelings, not externally driven:

... as long as it's, it's, something that, you know, you feel comfortable within your competence, because I think that's where sometimes, some of my colleagues have got more experience in sexual health, whereas I haven't so it might be something that I'll say 'I'm not comfortable. I would refer you to this service...' FG1-P2

Obsolete or duplicate codes were also removed, for example the original codebook included an 'advisory role' code, but on review the 'team role' code was deemed to be more appropriate.

Thematic analysis identified five themes each comprising several subthemes. Figure 1 depicts the themes as a sunburst chart. The size of each segment reflects the number of references to the item, and hence the relative importance of the topic to the participants. The inner ring contains the themes, with subthemes radiating out.

Figure 2 is a concept map depicting the hierarchy and interrelationships between themes and subthemes. Table 4 lists the themes and sub themes, their code book descriptions, and illustrative quotes from the participants.

The five themes identified were 'Staff', 'Self', 'Governance,' 'Practical aspects' and 'Patient care'. Some subthemes did not fall easily under any of these themes, rather they linked disparate themes or subthemes, and are described as orphan themes. These were 'Conflict of interest', 'Covid,' 'Undergraduate prescribing', and 'Good advice.'

\section{Staff}

This was the most frequently mentioned theme, particularly in relation to the clinical team but also to managers. The theme described the relationship between participants and senior and junior medical staff as well as other team members. Differences were highlighted in interactions between participants and senior or junior medical staff. The role within the clinical team was described and who lead on decision making. A lack of awareness of non-medical prescribing was identified by some, mainly physiotherapist, participants. Managers who prescribed were more supportive compared with non-prescribing managers, who may be unaware of prescribing governance issues. The 'Managers' subtheme linked to 'Training' and 'CPD' through the provision of funding and time.

Table 3 Brief participant demographic data

\begin{tabular}{llllll}
\hline Participant ID & Profession & Practice area & $\begin{array}{l}\text { Years qualified in } \\
\text { profession }\end{array}$ & Active prescriber & Focus Group \\
\hline FG1-P1 & Pharmacist & Ward, secondary care & $16-20$ & Yes & One \\
FG1-P2 & Pharmacist & Clinic, secondary care & $16-20$ & Yes & One \\
FG1-P3 & Pharmacist & Ward, secondary care & $6-10$ & Yes & One \\
FG2-P1 & Physiotherapist & Clinic, primary care & $16-20$ & Yes & Two \\
FG2-P2 & Pharmacist & Clinic, secondary care & $6-10$ & Yes & Two \\
FG2-P3 & Physiotherapist & Ward, secondary care & $16-20$ & Yes & Two \\
FG2-P4 & Pharmacist & Ward, secondary care & $16-20$ & Yes & Two \\
FG2-P5 & Physiotherapist & Clinic, primary care & $>21$ & Yes & Two \\
FG2-P6 & Pharmacist & Clinic, secondary care & $11-15$ & No, never prescribed & Two \\
FG2-P7 & Pharmacist & Ward, secondary care & $11-15$ & Two \\
\hline
\end{tabular}




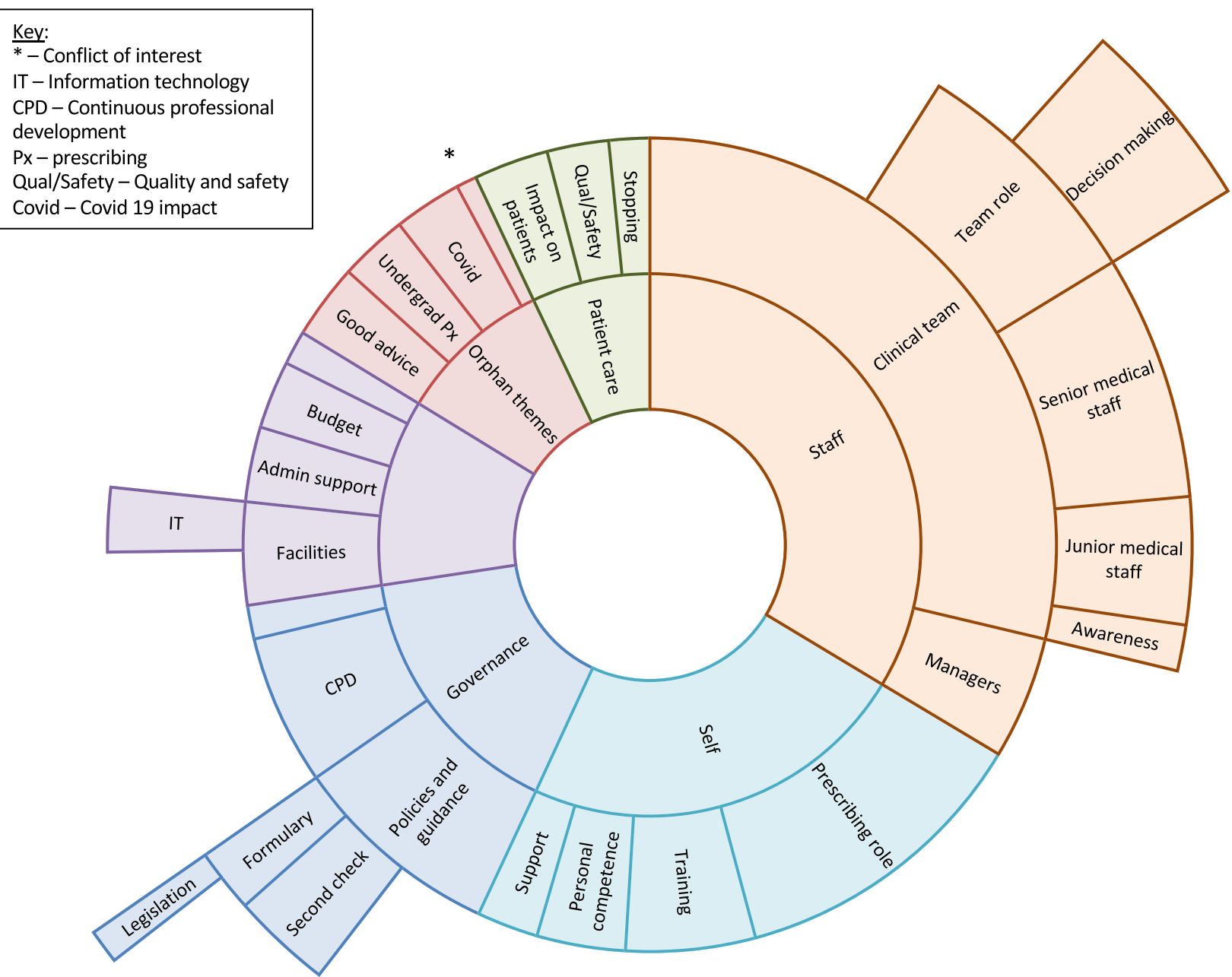

Fig. 1 Sunburst chart depicting the themes and subthemes, and their relative importance as indicated by area of segment

\section{Self}

This was the second most important theme, describing the participants' practice. It encompassed the role prescribing took within their job and, for some, the challenges associated with incorporating this into their existing role, as well as prescribing within their personal competence, and support they gained from others, such as the clinical team. The theme highlighted training aspects including access to, and skills gained on, the course. The 'Prescribing role' subtheme linked to the 'Stopping' subtheme as part of 'Patient care'.

\section{Governance}

This theme incorporates aspects such as policies and guidelines supporting NMP, organisation NMP registers, formulary and continuing professional development (CPD). Participants highlighted other policies affecting their practice, including accountability for patient care, which may influence senior medical approach to non-medical prescribing. Two minor subthemes were identified, which were profession specific: 'Legislation' affecting physiotherapists and 'Second check' affecting pharmacists.

\section{Practical aspects}

This theme incorporates those resources required to undertake prescribing, such as access to clinic rooms, information technology, appropriate budget and administrative support. Administration time was built into the roles for physiotherapist participants, whereas pharmacist participants described a lack of provision for administration time.

\section{Patient care}

This theme incorporates aspects of patient care including the impact on patients by ensuring prescriptions were appropriate and completed in a timely manner. Other benefits included improvements in quality and safety for 

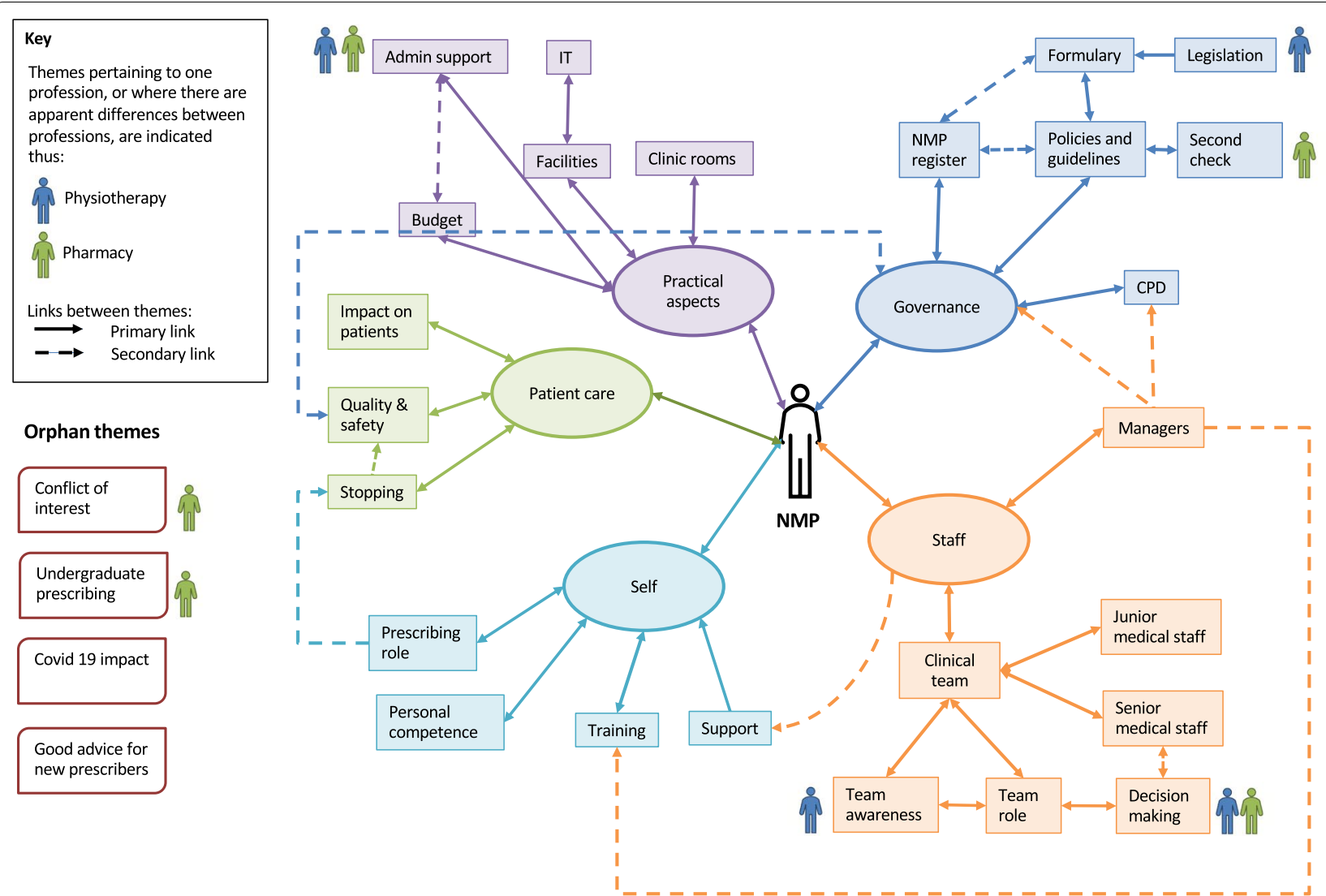

Fig. 2 Concept map of hierarchical structure depicting interrelationship between themes and sub themes

example by stopping inappropriate medication and having sufficient clinic time to check adherence. 'Quality and safety' linked with 'Governance'.

\section{Orphan themes}

Two of these themes were only mentioned by pharmacist participants and they were 'Conflict of interest' and 'Undergraduate prescribing. Several participants highlighted the impact the Covid-19 pandemic had on their practice and the final theme collated the advice the participants would give to new prescribers.

\section{Discussion}

This study enabled an in-depth investigation of issues affecting pharmacist and physiotherapist non-medical prescribers. Participants' lived experiences supported further exploration of the findings from a Delphi study [15]. Five themes, describing the experiences of the participants were identified.

\section{Themes}

The theme of "Staff" reflected the previous Delphi findings whereby the clinical team (medical, nursing and peer support) accounted for approximately $40 \%$ of factors affecting NMP achieving consensus [15], and further confirming the role of medical professionals and colleagues in supporting NMP, identified in the preceding review [14]. This is unsurprising as all participants described working collaboratively to share the patient caseload, within a multidisciplinary team usually led by a medical professional. Traditionally senior medical staff were accountable for the patient's care, and team members had closely defined roles. More latterly the move has been towards advanced practice in the non-medical professions, to develop a flexible workforce that is able to adopt innovative ways of working. This was described in the $2017 \mathrm{draft}$ workforce strategy, which highlighted the increasing demand on the NHS, and the limited number of clinicians to provide care [36], and which built on earlier work such as developing primary care services [9, 37]. In addition, NMP courses require the trainee to complete a period of practice-based training supervised by an experienced prescriber. Until recently all regulatory bodies required this trainer to be a member of the medical profession, fostering closer links between 


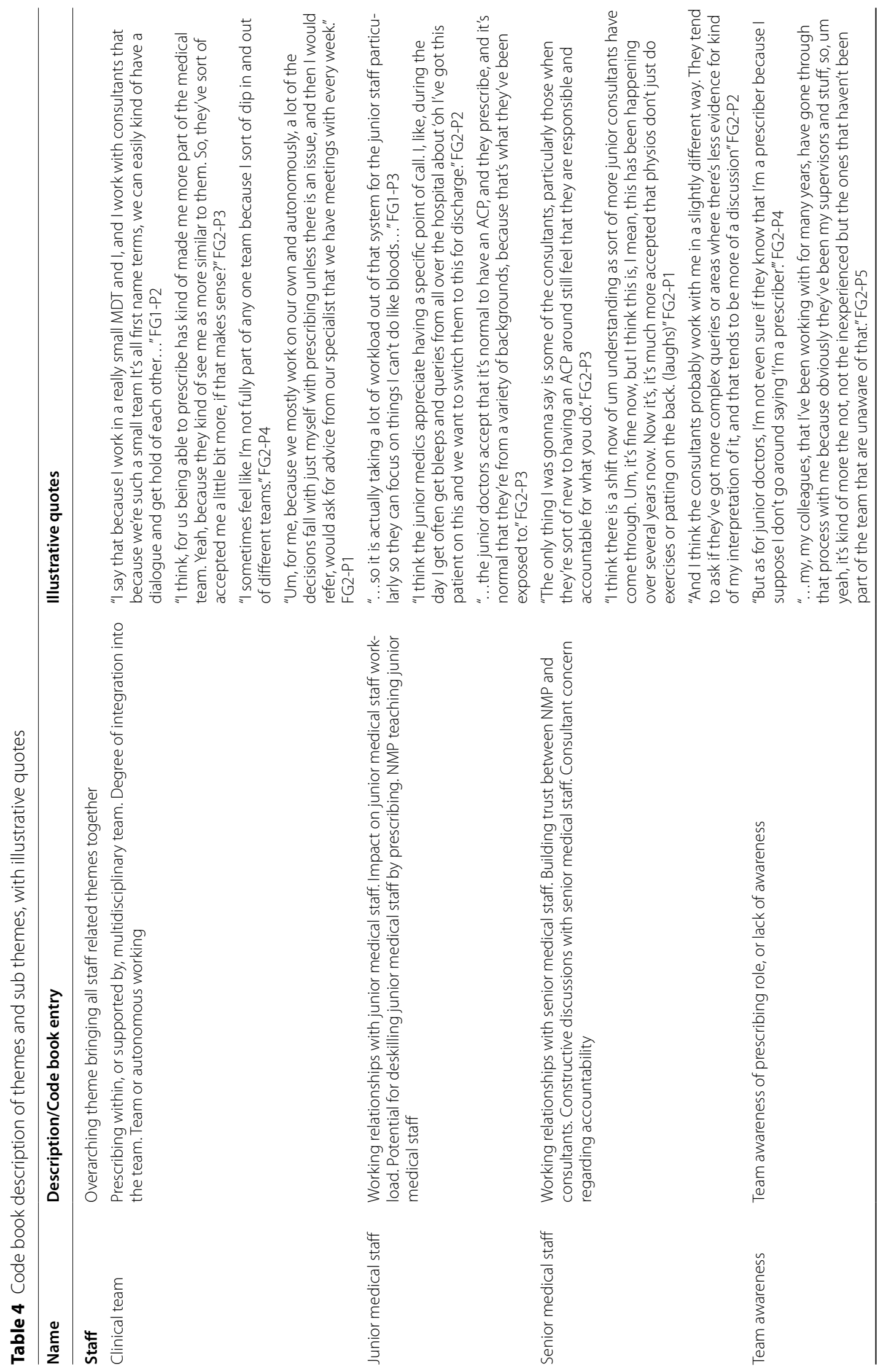




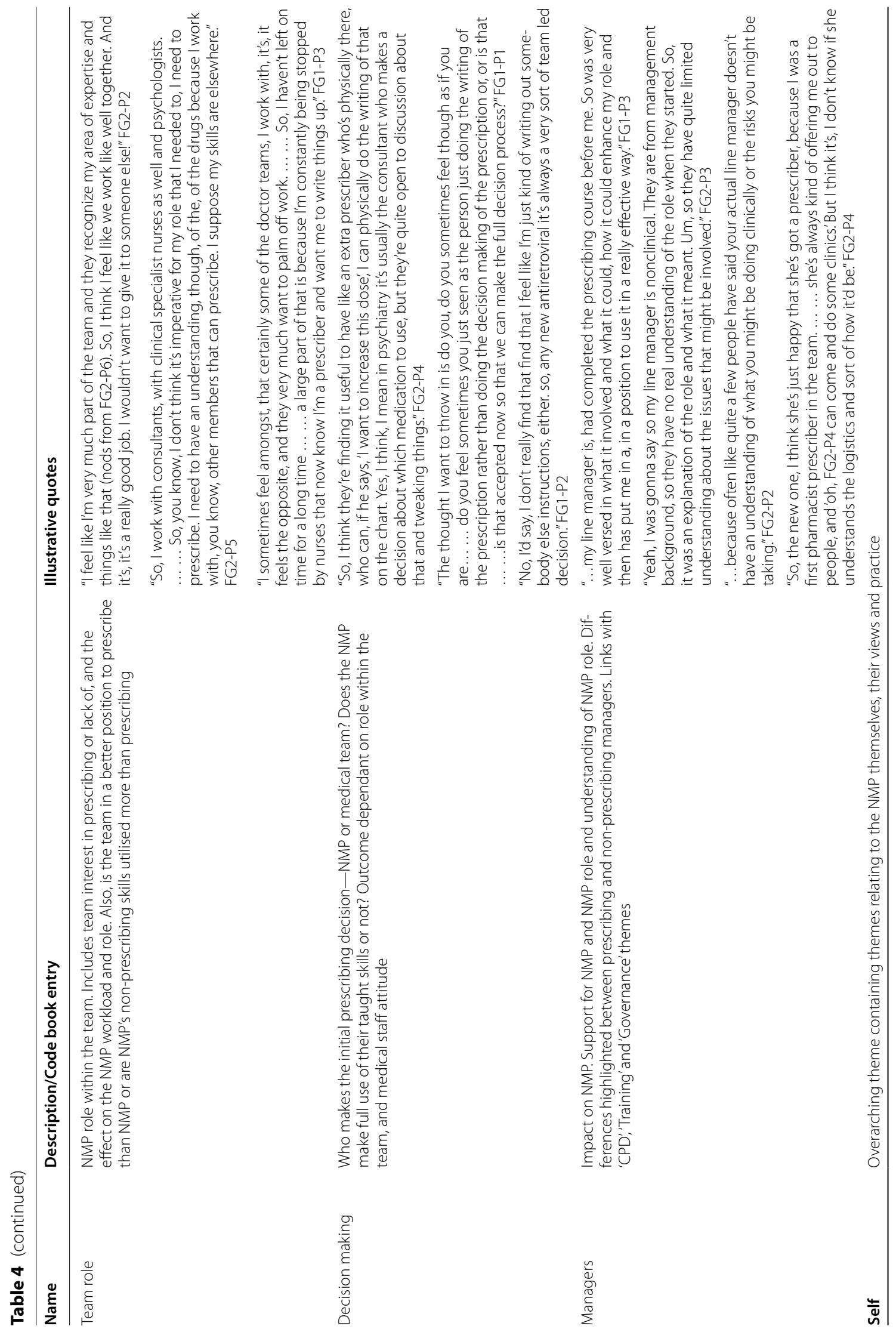




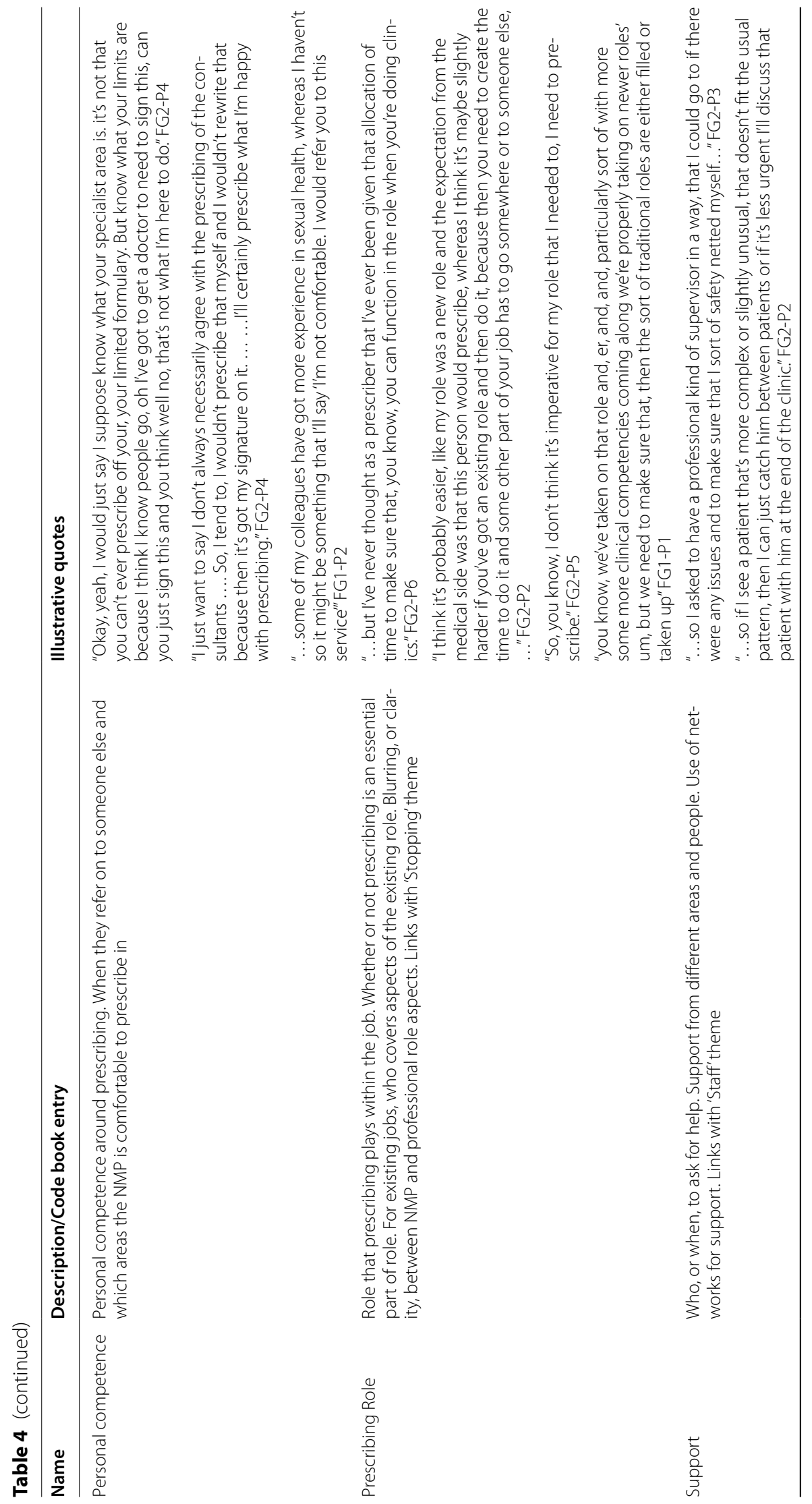




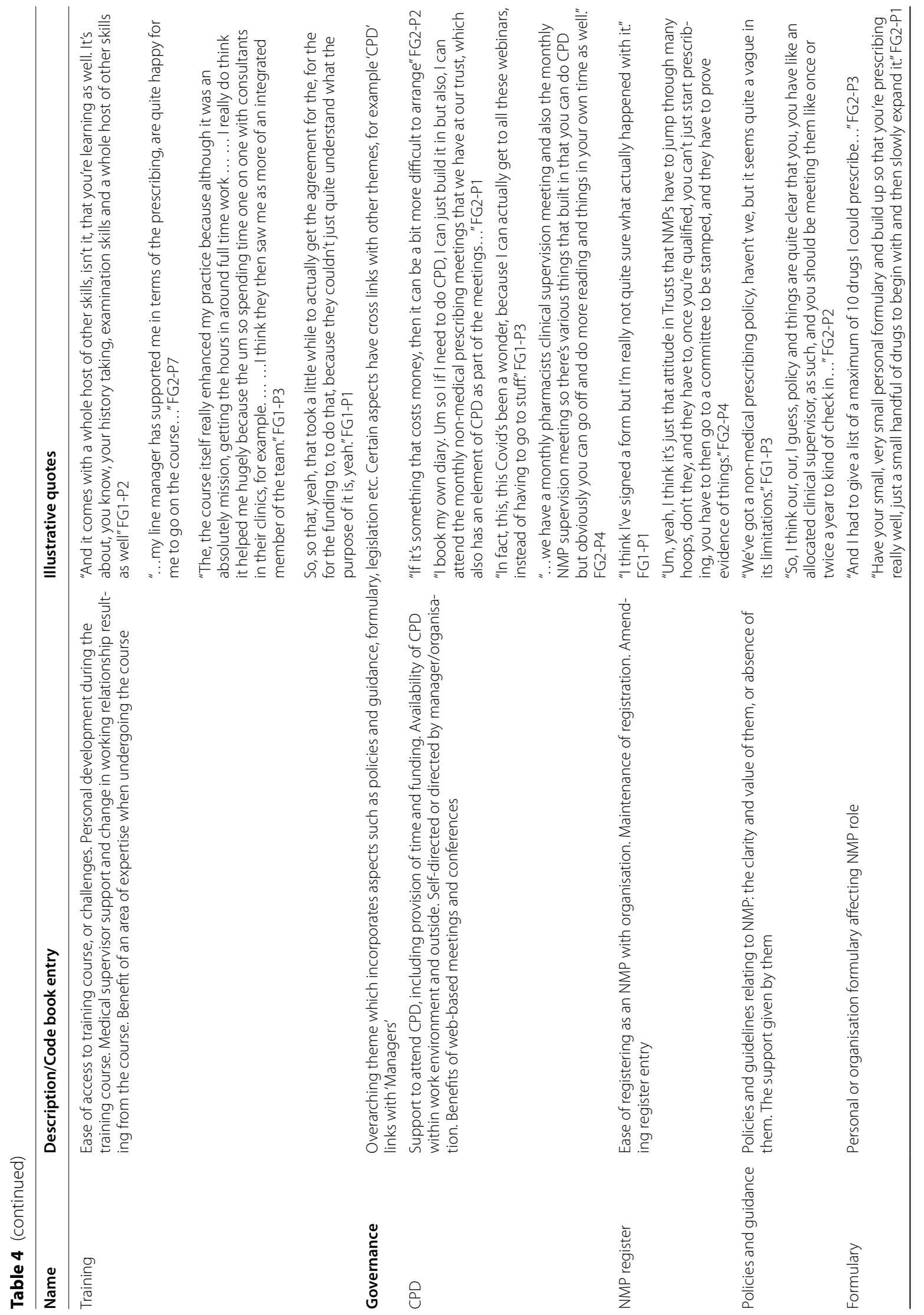




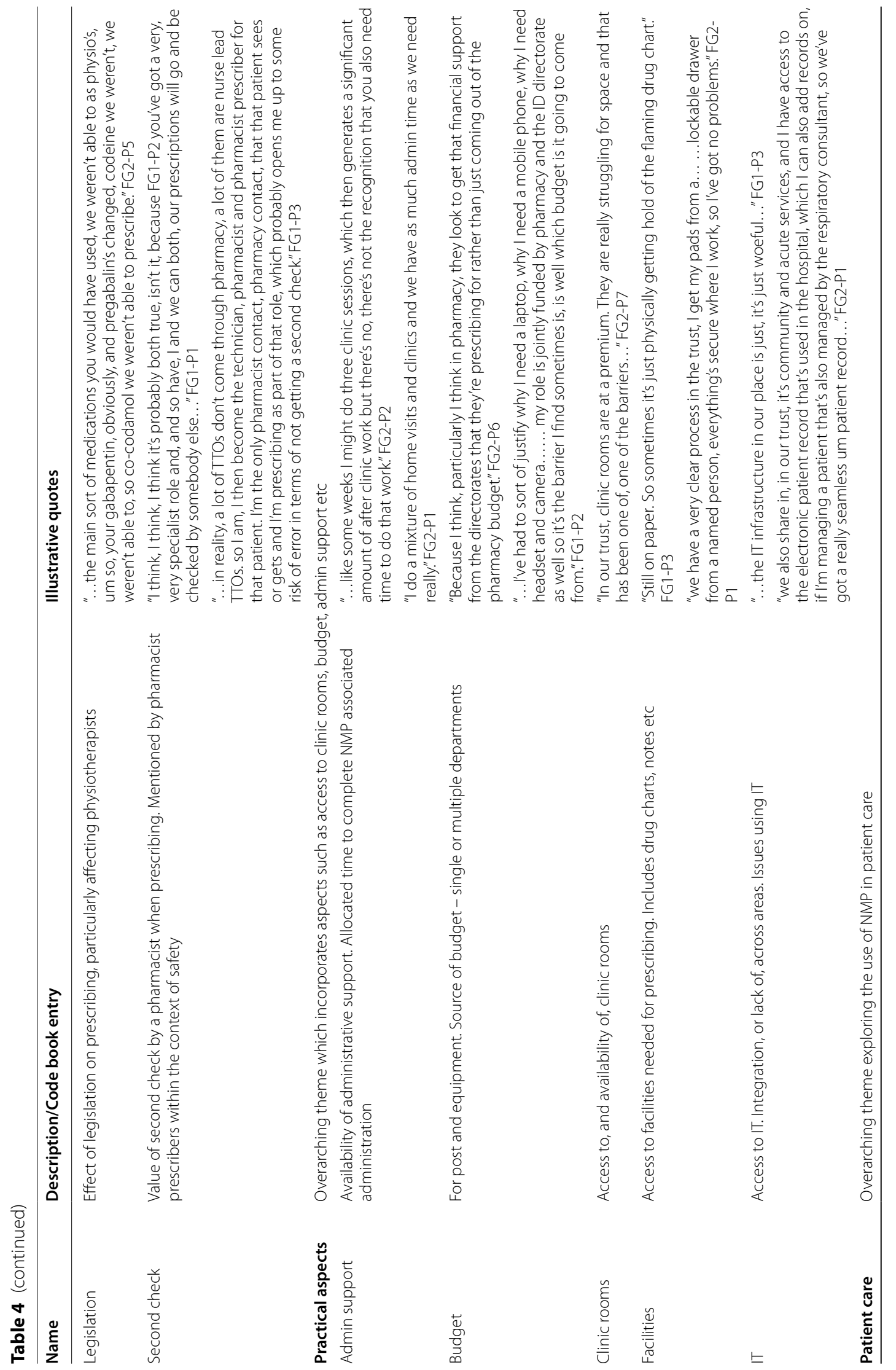




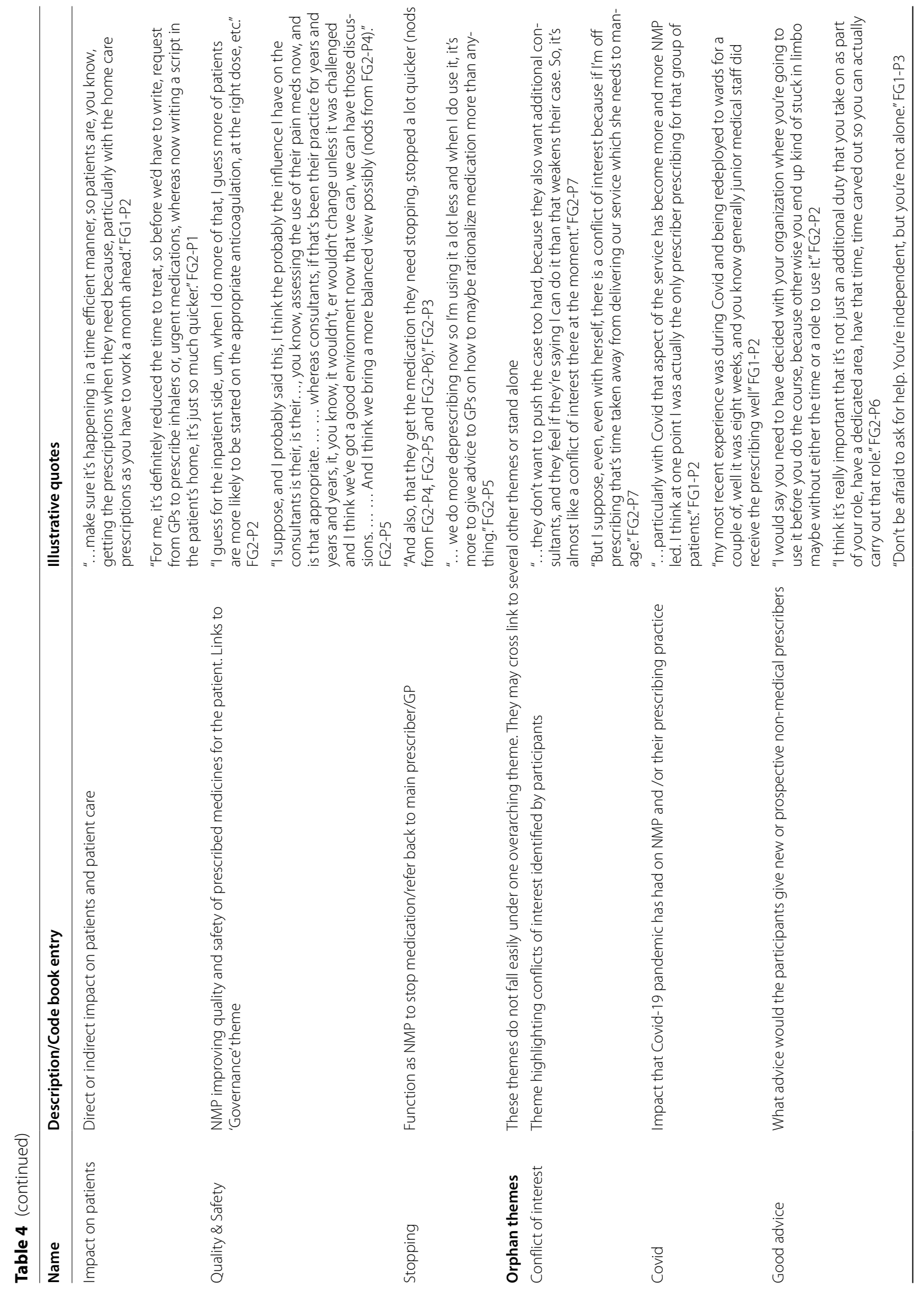




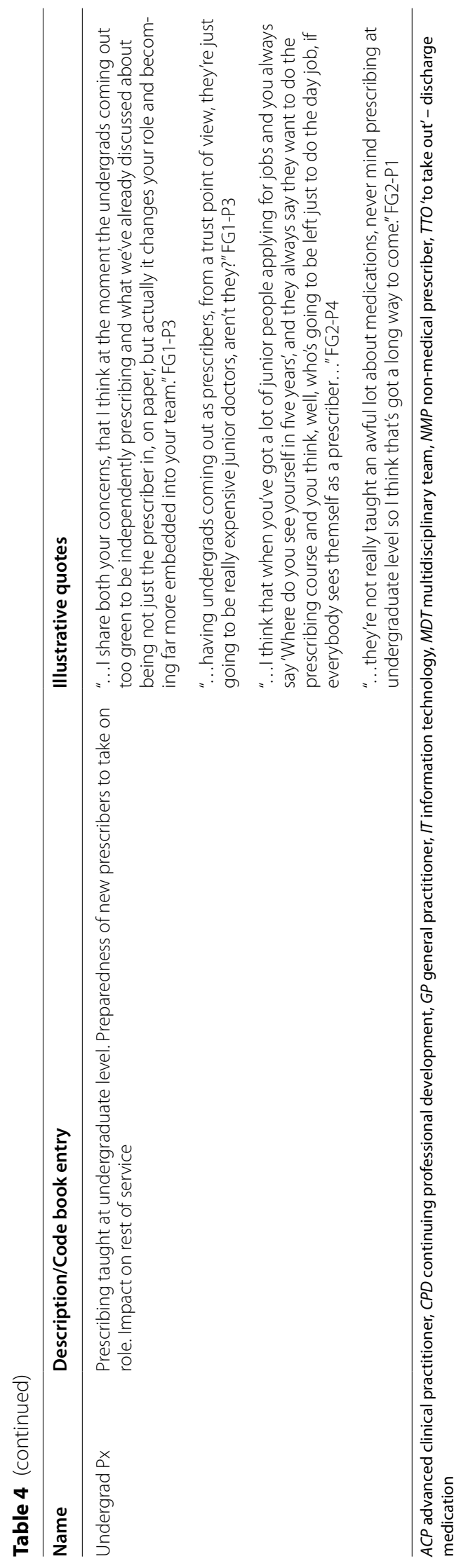


trainer and trainee, which many participants commented on.

The "Self" theme, accounting for approximately a quarter of all references, focused on the "Prescribing role", the role that prescribing had within the participant's job and whether prescribing was integral to that role. All prescribers are required to prescribe within their scope of practice and the prescriber's role implicitly defines that scope, together with guidance from regulatory and professional bodies [38-40]. Some pharmacist prescribers described challenges when prescribing had been added into their existing role, implying that for this group, the potential impact of prescribing had not been fully considered.

The "Practical aspects" and Governance" themes together highlighted the importance of ensuring adequate facilities for the prescriber, and a strong governance framework to support their prescribing practice. Covid-19 was found to affect some prescribers, either by altering how they practice, or by temporary changes to their role, as found by the "Covid-19" theme. However, changes brought about by the Covid-19 pandemic also appeared in the "CPD" theme, with many participants describing online conferences and meetings becoming routine practice; enabling participation by a wider audience.

The relatively limited number of references to patient care may be considered surprising when compared with the Delphi study, where the top ranked statement concerned the effectiveness and benefits of prescribing for patients [15]. However, this finding partially reflects the different research methods, with Delphi seeking consensus whereas focus groups enable deeper exploration of lived experiences of the participants. It also reflects the topics chosen for discussion, which were those where there were areas of potential disagreement between the two prescribing professions, and hence patient care was a subsidiary aspect of the discussion.

\section{Inter-dependencies}

The previous review exploring barriers and facilitators to non-medical prescribing identified that many of the factors involved were inter-dependent [14]. The experiences of the participants in this study supported this finding, with the important secondary co-dependencies depicted in Fig. 2. The "Quality and safety" theme was interdependent with all aspects of the "Governance" theme, resulting in improved care for patients. For example, participant FG2-P5 described constructive discussions with senior medical staff, informed by policies and guidance, resulting in team-wide changes in prescribing practice and improved patient care. For pharmacy managers, there was an implicit conflict between service delivery and governance, inferred by the "Second check" theme. Pharmacists are experts in medicines [41]; clinically screening prescriptions, the so called 'second check', to ensure appropriateness for the patient. Pharmacy managers are required to maintain the governance structure surrounding medicines supply, within a limited staffing establishment, and this can result not only in limiting time for pharmacist prescribing, but also difficulty in providing the second check. Evidence indicates that pharmacist prescribers make fewer errors than medical staff [42], but pharmacist participants perceived that they had been left without an important safety net. Further co-dependencies described by participants included the impact on senior medical staff of policies regarding patient accountability, with concern by some senior medical staff that they were accountable for the non-medical prescriber's actions. This lack of clarity regarding accountability was identified in the previous review [14]. The prescribing competency framework for all prescribers states that the prescriber is accountable for their prescribing decisions [39], however if a policy regarding patient accountability states that the consultant is responsible for the actions of their entire team, then this could result in confusion.

\section{Inter-professional differences}

Differences were highlighted between professions, many of which could be anticipated from the way in which each profession traditionally works. For physiotherapists, prescribing forms another treatment option when caring for patients, fitting in to existing roles such as in musculoskeletal clinics [43], whilst also supporting the development of new roles based on existing skills [10]. For the secondary care pharmacist participants, prescribing in many instances was in addition to their existing role, without due consideration to restructuring job plans to allow sufficient time. Consequently, physiotherapist participants felt well-supported for administration time, whereas for the pharmacist participants, unless expressly included in their job plan, administration time was a source of stress. Similarly, pharmacist participants, used to working in a team, described a team approach to decision making, compared with physiotherapists, used to planning treatment courses for patients, who were more inclined to make their own decisions.

For the physiotherapist participants, the choice of medicines that they can prescribe is limited by their professional scope of practice and legislation [38, 44], compared with pharmacists who can prescribe any medication, except certain drugs for the treatment of addiction $[45,46]$. For the physiotherapists, probable changes in controlled drug legislation have the potential to influence how advanced practice roles develop, particularly if physiotherapists continue to have restricted access to 
controlled drugs [47]. One physiotherapist participant described the constraints imposed by controlled drug legislation in chronic pain management, but commented that current guidance was moving away from drug treatment and hence expanding the choice of controlled drugs physiotherapists could prescribe may have limited impact in their case $[47,48]$.

Physiotherapist participants were more likely to describe lack of awareness of physiotherapist prescribing by the clinical team, than pharmacist participants. This reflects both the relatively short time span in which physiotherapists have had prescribing rights (independent prescribing rights since 2013) and the small numbers registered as prescribers (1017 independent prescribers in 2019) [17, 19]. In comparison, pharmacists gained independent prescribing rights in 2006, with 8077 independent prescribers on the register in 2019 [49, 50].

Planned changes in pharmacist pre-registration training, including at undergraduate level, will result in newly registered pharmacists registering as independent prescribers [51]. Pharmacist participants expressed concerns about this development, including detraction from training aspects and potential exacerbation of prescribing errors, as previously identified with junior medical staff [52]. The participants placed their views in the context of their own prescribing training, highlighting the struggle that less experienced pharmacists had with the course, and commenting that routine pharmacy work still needed addressing. However, the development is in line with the Carter report and draft workforce strategy, which both envisaged a clinical pharmacy workforce, with pharmacy technicians adopting some of the traditional pharmacist roles $[36,53]$. The concerns expressed by pharmacist participants regarding time pressures to complete their tasks suggest that advanced pharmacy technician roles, which would release pharmacist time for prescribing, have still to be adopted.

Trustworthiness of the data is supported by the approach to analysis. Full, in-depth discussion of the findings by all authors, with challenge of the derived themes to ensure that they reflected the participants experiences was undertaken. The differences in background and experiences of the research team composition ensured that EGC's longstanding prescribing experience in critical care, and possible preconceptions, were counterbalanced by the other team members, who were non-prescribers but clinicians in both physiotherapy and pharmaceutical fields. Data saturation was achieved, with the themes and main subthemes identified by each focus group and profession. This is supported by the answers to the final question regarding advice to new prescribers, added as a positive end note to each session. No new ideas were articulated but participants emphasised the need for a prescribing role, ensuring facilities were in place beforehand, asking for advice and not being pressurised to prescribe medication that they deemed outside their personal competence.

\section{Strengths and limitations}

The study allowed in-depth discussion of issues affecting pharmacist and physiotherapist prescribers, with ideas developed by the participants throughout the discussion. Participants drew on their experiences to describe issues affecting them, allowing a greater understanding of the background and contributory factors. As the themes were derived directly from these lived experiences, they acquired content and face validity.

The virtual platform, with choice of dates and times, allowed participants to join who may otherwise have been unable to because of constraints such as work commitments.

The Covid-19 pandemic limited recruitment: in particular fewer physiotherapist participants were recruited than planned. However, findings appeared unaffected with no new themes emerging from the second focus group. This supports the assertion that data saturation was achieved for the major themes identified.

It is acknowledged that recruitment may have been enhanced by widening the geographical catchment area. However, it was possible that some of the variation seen in the previous Delphi results [15] may have arisen from the wide range of practice and geographic areas in which participants were employed. Therefore a deliberate decision was made to limit recruitment to pharmacist and physiotherapist prescribers working in the NHS West Midlands area (either primary or secondary care), to reduce the risk of introducing variability into the findings.

\section{Conclusion}

The key finding from this study related to the theme of collaborative working with the clinical team; emphasising the impact this has on successful implementation of NMP. When their role was specifically designed to include prescribing, this was a benefit for pharmacist participants. Multiple factors contribute to the themes of governance, practical aspects and patients, and each factor is important for successful implementation of NMP. Crucially, the identified themes and subthemes cannot be considered in isolation but are inter-dependent on each other.

Differences between the professions were illustrated from the analysis, most reflecting the way each profession practises and, for pharmacists, the way that prescribing has been introduced into their role. For the pharmacists, managers need to address the skill mix to enable pharmacist prescribers to practise with support. 
To ensure NMP is fully enabled, all aspects must be fully scoped before recruiting or training a non-medical prescriber. Failure to do so may limit full utilisation of prescribing skills and result in a poorly motivated workforce.

\section{Abbreviations}

CPD: Continuing professional development; IPA: Interpretative Phenomenology Analysis; NHS: National Health Service; NMP: Non-medical prescribing; UK: United Kingdom.

\section{Supplementary Information}

The online version contains supplementary material available at https://doi. org/10.1186/s12913-022-07559-5.

Additional file 1. Focus group topic guide.

Additional file 2. Consolidated criteria for reporting qualitative studies(COREQ): 32-item checklist.

\section{Acknowledgements}

Not applicable

\section{Authors' contributions}

EGC conceived the protocol, conducted the study, analysed the data, wrote the first draft, and edited the manuscript. JM and AR conceived the protocol, reviewed the data analysis, and edited the manuscript. The author(s) read and approved the final manuscript.

\section{Funding}

The author(s) received no specific funding for this work.

\section{Availability of data and materials}

The datasets used and/or analysed during the current study are available from the corresponding author on reasonable request.

\section{Declarations}

\section{Ethics approval and consent to participate}

Ethical approval for the study was obtained from the University of Birmingham's Science, Technology, Engineering and Mathematics Ethical Review Committee (ERN_19-1900). All methods were caried out in accordance with the relevant guidance and regulations. All participants gave written informed consent, including for digital audio recording, prior to commencement of the focus group.

\section{Consent for publication}

Not applicable.

\section{Competing interests}

The author(s) declare(s) that they have no competing interests.

\section{Author details}

${ }^{1}$ School of Pharmacy, Institute of Clinical Sciences, College of Medical and Dental Sciences, University of Birmingham, Birmingham, UK. ${ }^{2}$ School of Physical Therapy, Western University, London, Canada.

Received: 7 August 2021 Accepted: 24 January 2022

Published online: 18 February 2022

\section{References}

1. Department of Health. Improving Patients' Access to Medicines: A Guide to Implementing Nurse and Pharmacist Independent Prescribing within the NHS in England. Leeds: Department of Health; 2006.
2. Department of Health and Social Security. Neighbourhood nursing: a focus for care. (The Cumberlege Report). London: HMSO; 1986.

3. Department of Health. Review of prescribing, supply and administration of medicines. Final report (Crown II Report). London: The Stationery Office; 1999. (http://webarchive.nationalarchives.gov.uk/2013010514 3320/http://www.dh.gov.uk/prod_consum_dh/groups/dh_digitalass ets/@dh/@en/documents/digitalasset/dh_4077153.pdf).

4. Non-medical prescribing [https://bnf.nice.org.uk/guidance/non-medic al-prescribing.html ]

5. The Health Foundation. Staffing matters; funding counts. London: The Health Foundation; 2016. (http://www.health.org.uk/sites/health/files/ StaffingMattersFundingCounts.pdf).

6. NHS England. Five Year Forward View. London: The Stationery Office; 2014. (https://www.england.nhs.uk/wp-content/uploads/2014/10/5yfvweb.pdf).

7. NHS Wales. A Planned Primary Care Workforce for Wales: Approach and development actions to be taken in support of the plan for a primary care service in Wales up to 2018. Cardiff: Welsh Assembly; 2015.

8. Graham-Clarke E, Rushton A, Noblet T, Marriott J. Non-medical prescribing in the United Kingdom National Health Service: A systematic policy review. PLoS ONE. 2019;14(7):e0214630.

9. Health Education England. The future of primary care: Creating teams for tomorrow. London: Health Education England; 2015. (https://www.hee. nhs.uk/sites/default/files/documents/The\%20Future\%20of\%20Primary\% 20Care\%20report.pdf).

10. Health Education England, NHS England, Skills for Health. Musculoskeletal core capabilities framework for first point of contact practitioners. London: Health Education England; 2018. (https://www.skillsforhealth. org.uk/news/latest-news/item/689-new-musculoskeletal-core-capabiliti es-framework).

11. Royal Pharmaceutical Society. Improving care for people with Long Term Conditions. London: Royal Pharmaceutical Society; 2016. p. 20 (https:// www.rpharms.com/Portals/0/RPS\%20document\%20library/Open\%20acc ess/Policy/LTC\%20-\%20England.pdf).

12. Latter S, Blenkinsopp A, Smith A, Chapman S, Tinelli M, Gerard K, Little P, Celino N, Granby T, Nicholls P: Evaluation of nurse and pharmacist independent prescribing. University of Southampton; Keele University; 2010: 374. Available from: https://eprints.soton.ac.uk/184777/3/ENPIPfullreport. pdf.

13. Courtenay M, Carey N, Stenner K. An overview of non medical prescribing across one strategic health authority: a questionnaire survey. BMC Health Serv Res. 2012;12:138.

14. Graham-Clarke E, Rushton A, Noblet T, Marriott J. Facilitators and barriers to non-medical prescribing - A systematic review and thematic synthesis. PLOS ONE. 2018;13(4):e0196471.

15. Graham-Clarke E, Rushton A, Marriott J. A Delphi study to explore and gain consensus regarding the most important barriers and facilitators affecting physiotherapist and pharmacist non-medical prescribing. PLoS ONE. 2021;16(2):e0246273.

16. General Pharmaceutical Council. Council Meeting. London: General Pharmaceutical Council; 2019. (https://www.pharmacyregulation.org/sites/ default/files/document/gphc-council-meeting-papers-01-02-2019.pdf).

17. Number of registrants with prescribing rights - August 2019 [https:// www.hcpc-uk.org/resources/freedom-of-information-requests/2019/ number-of-registrants-with-prescribing-rights---august-2019/ ]

18. The National Health Service (Miscellaneous Amendments Relating to Independent Prescribing) Regulations 2006, Stat. 913. London: The Stationery Office; 2006.

19. The Human Medicines (Amendment) Regulations 2013, Stat. 1855 London: The Stationery Office; 2013.

20. Peat G, Rodriguez A, Smith J. Interpretive phenomenological analysis applied to healthcare research. Evid Based Nurs. 2019;22(1):7-9.

21. Finch H, Lewis J, Turley C. Focus Groups. In: Ritchie J, Lewis J, Nicholls CM, Ormston R, editors. Qualitative Research Practice. 2nd ed. London: Sage Publications Ltd; 2014. p. 211-42.

22. Hennink MM. Introduction to focus group research. In: International Focus Group Research: A Handbook for the Health and Social Sciences. Cambridge: Cambridge University Press; 2007. p. 1-17 (https://www. cambridge.org/core/books/international-focus-group-research/intro duction-to-focus-group-research/CE2C6D772805302A6A522DB57 EB3CF6F). 
23. Hennink MM, Kaiser BN, Weber MB. What Influences Saturation? Estimating Sample Sizes in Focus Group Research. Qual Health Res. 2019:29(10):1483-96.

24. Guest G, Namey E, McKenna K. How Many Focus Groups Are Enough? Building an Evidence Base for Nonprobability Sample Sizes. Field Methods. 2017;29(1):3-22.

25. Hennink MM. Number of groups and group size. In: International Focus Group Research: A Handbook for the Health and Social Sciences. Cambridge: Cambridge University Press; 2007. p. 135-51 (https://www.cambr idge.org/core/books/international-focus-group-research/number-ofgroups-and-group-size/B1AF4CD1C4FFC1E76ED55B1240AD82C4).

26. Hennink MM. Conducting the group discussion. In: International Focus Group Research: A Handbook for the Health and Social Sciences. Cambridge: Cambridge University Press; 2007. p. 165-92 (https://www.cambr idge.org/core/books/international-focus-group-research/conductingthe-group-discussion/626BE4ACD9373F43DAE93180A015488D).

27. Ritchie J, Spencer L. Qualitative data analysis for applied policy research. In: Analyzing Qualitative Data. edn 1. Edited by Bryman A, Burgess RG: Taylor \& Francis Books Ltd; 1994. p. 173-94.

28. Arthur S, Mitchell M, Lewis J, Nicholls CM. Designing fieldwork. In: Ritchie J, Lewis J, Nicholls CM, Ormston R, editors. Qualitative Research Practice. 2nd ed. London: Sage Publications Ltd; 2014. p. 147-76.

29. Coronavirus disease (COVID-19) advice for the public [https://www.who. int/emergencies/diseases/novel-coronavirus-2019/advice-for-public

30. Rupert DJ, Poehlman JA, Hayes JJ, Ray SE, Moultrie RR. Virtual Versus InPerson Focus Groups: Comparison of Costs, Recruitment, and Participant Logistics. J Med Internet Res. 2017;19(3):e80-e80.

31. Hill JC, Patterson C. Assessment from a Distance: A Case Study Implementing Focus Groups at an Online Library. Coll Undergrad Lib. 2013;20(3-4):399-413.

32. Onwuegbuzie AJ, Dickinson WB, Leech NL, Zoran AG. A Qualitative Framework for Collecting and Analyzing Data in Focus Group Research. Int J Qual Methods. 2009:8(3):1-21.

33. Braun V, Clarke V. Using thematic analysis in psychology. Qual Res Psychol. 2006;3(2):77-101

34. Vaismoradi M, Turunen $\mathrm{H}$, Bondas T. Content analysis and thematic analysis: Implications for conducting a qualitative descriptive study. Nurs Health Sci. 2013;15(3):1442-2018.

35. Tong A, Sainsbury P, Craig JC. Consolidated criteria for reporting qualitative research (COREQ) A 32-item checklist for interviews and focus groups. Int J Qual Health Care. 2007;19(6):349-57.

36. Public Health England. Facing the Facts, Shaping the Future: A draft health and care workforce strategy for England to 2027. London: Public Health England; 2017.

37. NHS Wales. Our Plan for Primary Care in Wales up to March 2018. Cardiff: Welsh Assembly; 2014.

38. Practice Guidance for Physiotherapist Supplementary and/or Independent Prescribers (4th Edition) [https://www.csp.org.uk/system/files/publi cation_files/PD026_PracticeGuidancePrescribing_4thEd_2018.pdf ]

39. Royal Pharmaceutical Society. A competency framework for all prescribers. London: Royal Pharmaceutical Society; 2016. (https://www.rpharms. com/resources/frameworks/prescribers-competency-framework).

40. General Pharmaceutical Council. In practice: Guidance for pharmacist prescribers. London: General Pharmaceutical Council; 2019. (https:// www.pharmacyregulation.org/sites/default/files/document/in-practiceguidance-for-pharmacist-prescribers-february-2020.pdf).

41. What does a pharmacist do? [https://www.pharmacyregulation.org/ raising-concerns/raising-concerns-about-pharmacy-professional/whatexpect-your-pharmacy/what-does-0 ]

42. Baqir W, Crehan O, Murray R, Campbell D, Copeland R. Pharmacist prescribing within a UK NHS hospital trust: nature and extent of prescribing, and prevalence of errors. Eur J Hosp Pharm-Sci Pract. 2015:22(2):79-82.

43. Department of Health. The Musculoskeletal Services Framework - A joint responsibility: doing it differently. London: The Stationery Office; 2006. (http://webarchive.nationalarchives.gov.uk/20130124073659/http:// www.dh.gov.uk/prod_consum_dh/groups/dh_digitalassets/@dh/@en/ documents/digitalasset/dh_4138412.pdf)

44. The Misuse of Drugs (Amendment) (No. 2) (England, Wales and Scotland) Regulations 2015, Stat. 891. London: The Stationery Office; 2015.

45. The Misuse of Drugs (Amendment No. 2) (England, Wales and Scotland) Regulations 2012, Stat. 973. London: The Stationery Office; 2012.
46. The Human Medicines Regulations 2012, Stat. 1916. London: The Stationery Office; 2012.

47 England NHS. Consultation on proposed amendments to the list of controlled drugs that physiotherapists can independently prescribe across the United Kingdom. Leeds: NHS England; 2020.

48. Chronic pain (primary and secondary) in over 16s: assessment of all chronic pain and management of chronic primary pain [https://www. nice.org.uk/guidance/ng193 ]

49. Enventure Research. Survey of registered pharmacy professionals 2019 London: General Pharmaceutical Council; 2019. (https://www.pharm acyregulation.org/about-us/research/gphc-survey-registered-pharmacyprofessionals-2019)

50. The Medicines for Human Use (Prescribing) (Miscellaneous Amendments) Order 2006, Stat. 915. London: The Stationery Office; 2006.

51. General Pharmaceutical Council. Standards for the initial education and training of pharmacists. London: General Pharmaceutical Council; 2021. (https://www.pharmacyregulation.org/sites/default/files/document/ standards-for-the-initial-education-and-training-of-pharmacists-january2021.pdf).

52. Dornan $T$, Ashcroft $D$, Heathfield H, Lewis P, Miles J, Taylor D, Tully M, Wass $\checkmark$. An in depth investigation into causes of prescribing errors by foundation trainees in relation to their medical education. EQUIP study - final report. London: General Medical Council; 2009. (https://www.gmc-uk. org/-/media/documents/final-report-prevalence-and-causes-of-presc ribing-errors_pdf-28935150.pdf).

53. Lord Carter of Coles. Operational productivity and performance in English NHS acute hospitals: Unwarranted variations. London: The Stationery Office; 2016. (https://www.gov.uk/government/publications/productivi ty-in-nhs-hospitals).

\section{Publisher's Note}

Springer Nature remains neutral with regard to jurisdictional claims in published maps and institutional affiliations.

Ready to submit your research? Choose BMC and benefit from:

- fast, convenient online submission

- thorough peer review by experienced researchers in your field

- rapid publication on acceptance

- support for research data, including large and complex data types

- gold Open Access which fosters wider collaboration and increased citations

- maximum visibility for your research: over $100 \mathrm{M}$ website views per year

At BMC, research is always in progress.

Learn more biomedcentral.com/submissions 